\title{
Assessment of compressive strength of peat soil with sawdust and Rice Husk Ash (RHA) with hydrated lime as additive
}

\author{
Noorfaizah Hamzah ${ }^{*}$, Nur 'Ain Mat Yusof², and Muhammad Ihsan Haziq Mohd Rahimi' \\ ${ }^{1}$ Faculty of Civil Engineering, Universiti Teknologi MARA, Shah Alam, 40450, Selangor Malaysia \\ ${ }^{2}$ Faculty of Civil Engineering, Universiti Teknologi MARA Pahang, Bandar Tun Abdul Razak Jengka, Pahang, Malaysia
}

\begin{abstract}
Construction activities on peat soils are found to be extremely difficult as the soil is profound as soft soil and has low shear strength and high moisture content. Due to alternating swelling and shrinkage nature, it causes serious damage to the structure above it. This happens due to repetition of drying and wetting of soil. Stabilization of soil is commonly applied to improve the mechanical properties of soil prior to soil engineering works. This soil improvement method is advantageous and effective one by using waste materials. Waste in our country is divided in various types and it includes domestic wastes, industrial wasters, agricultural wastes etc. Because of difficulties to diminish these wastes without affect to environment and surroundings, it can be used as a stabilizing agent in the soil. Therefore, this experimental study carried out to evaluate the effect of Rice Husk Ash (RHA) and sawdust on engineering properties of the peat soil. The properties such as compaction and unconfined compressive strength are determined separately with sawdust and added of RHA in peat soil at a variety of percentages $(2.5 \%, 5 \%$ etc.) in addition small amount of constant rate of lime with $2 \%$ of the dry soil weight. By obtaining the results, it can deduce a promising and improving result in stabilizing the soil with sawdust and Rice Husk Ash in both economic and strength capacity. This will not only solve the waste disposal problem but also enhance the strength characteristics of soil significantly.
\end{abstract}

\section{Introduction}

Peat is a blend of broke down natural material shaped in a damp condition which arrives under adjusted climatic and topographic conditions This organic soil contains a mixture of decomposed plant materials and animal or specifically, it contains about. $75 \%$ organic matter. However, due to its properties and behind an interesting characteristics, it can cause biggest disasters to construction industry. This organic soil can affect and cause difficulties during construction works since it is low in shear strength but high in compressive deformation. Islam et al. (2008) stated that the peat soil has a low bearing capacity as it was affected by water table and woody debris on the sub surface [1]. As reflect, it faces crucial issues especially long-term consolidation settlement even under moderate loads. To avoid these circumstances, the soil must be stabilized, and strength is to be increased.

Numerous numbers of studies were conducted in purpose to stabilize peat soil with other mixtures like cement and bitumen. However, increases in the price of these stabilizing materials is affected to the increases in construction cost. To overcome the problem, rice husk ash (RHA) and hydrated lime was chosen where these materials are generated from the waste of industries and agricultural areas. Both materials can be used to stabilize the soil and avoid the problem to construction especially when the project is constructed on peat area. As suggested by our government to keep the earth green, RHA and hydrated lime is the best choice and used as alternative way to dispose the wastes and clear the environment surroundings in a beneficial manner.

Annually, it is estimated about 3.66 million tonnes of paddy residue is left in the fields. This value is forecasted will increase to 7 million tonnes per year towards the year 2020 due to emerging technology development in agriculture industries [2]. Paddy residue can be consisting of paddy straw and rice husk and these both residues are still not fully utilized. In fact, 0.48 million tonne of rice husk and about 108 tonnes produced in our world annually due to the emerging technological development in agro industry Rice Husk Ash (RHA) is one of the agricultural waste products that can get from rice husk. It is estimated that $40 \mathrm{~kg}$ of rice husk ash come from $1000 \mathrm{~kg}$ of rice which produced $200 \mathrm{~kg}$ of rice husk. The rice husk ash is produced by burning the rice husk in a furnace at about $6000{ }^{\circ} \mathrm{C}$ temperature for about 24 hours burning. Since the presence of silica in shapeless form, it will react with calcium hydroxide and free the heat and forms

\footnotetext{
* Corresponding author: noorfaizah1209@salam.uitm.edu.my
} 
cementitious compounds. About $67-90 \%$ of silica consist in rice husk [3]. The existence of the silica in the rice husk in the shapeless form and it is a pozzolanic material.

Based on previous researchers on the soil stabilization conducted by scholars, sawdust can be used as soil stabilizer. Sawdust is a by-product of wood from cutting and other activities that used wood and it is composed of fine particles of wood. It is always used to amend soils for horticultural crops consist of fruit and vegetable agriculture. The combination of sawdust and the soil will recover the soil structure, increase the nutrient holding capacity of sandy soils and improve the water drainage [4].

This study examined of peat soil and their reactions towards sawdust, rice husk ash and hydrated lime as a mixture. The physical properties of peat soil and treated soil with the variation amount of sawdust, rice husk ash and constant amount of hydrated lime were determined. The compaction test and Uniaxial Compressive Test (UCT) were used to determine the effect to the mechanical properties of soil to the mixture. The UCT were also used to evaluate the compressive strength of the treated soil.

\section{Materials and methods}

The peat soils were acquired from Jalan Sungai Panjang, Sungai Panjang, Sungai Besar, Selangor, Malaysia which the undisturbed samples were collected by using tube sampler at $0.5 \mathrm{~m}$ depth and sealed with plastic sealer. This type of sampler is used in order to verify no change of soil structure, void ratio and water content including in constituent and chemical properties. Meanwhile, the disturbed samples were taken by using hoe and shovel. Then the samples collected were stored in plastic container which used later for series of laboratory testing and sample preparation.

Besides that, the sawdust used for this study was collected from sawmills PIEZZOE Sdn Bhd Klang, Selangor. The soil passing through sieve No.40 is keeping in for oven drying at temperature of $105^{\circ} \mathrm{C}$. Next, the soil samples were mixing with different percentage of the sawdust with $0 \%, 2 \%, 3 \%, 4 \%$ and $5 \%$ respectively from the dry weight of the soil. The mixture is based on their optimum water content. The mixing process was done manually with proper care when preparing homogenous mixtures at each stage of mixing. The shear strength of soil samples which is its maximum resistance to shearing stresses were gained from a direct shear test.

Rice Husk Ash (RHA) was used as stabilizer agent in this study which it collected from LLH Biomass Sdn Bhd, Alor Setar, Kedah. Initially, the RHA is in dry condition. Resulting from burning of rice husk in open area, it can be observed that RHA is in black colour condition. This is a usual way of mills operators to dispose the rice husk before dumped to the landfill. The arrangement of treated soil is shown in Table 1.
Table 1. Sample preparation of peat soil with rice husk ash (RHA) and with hydrated lime as an additive

\begin{tabular}{|c|c|c|c|}
\hline Batch & Sample & Remarks & $\begin{array}{l}\text { Test to be } \\
\text { carried out }\end{array}$ \\
\hline 1 & $\begin{array}{c}\text { Peat soil } \\
(100 \%)\end{array}$ & $\begin{array}{l}\text { Disturbed } \\
\text { samples }\end{array}$ & \multirow{5}{*}{$\begin{array}{l}\text {-Moisture } \\
\text { content } \\
\text {-Specific } \\
\text { gravity } \\
\text {-Liquid Limit } \\
\text { Test } \\
\text {-Plastic Limit } \\
\text { Test } \\
\text {-Compaction } \\
\text { Test } \\
\text {-UCT }\end{array}$} \\
\hline 2 & $\begin{array}{l}\text { Peat soil + } \\
2.5 \% \text { RHA } \\
+2 \% \text { Lime }\end{array}$ & $\begin{array}{c}\text { The peat soil } \\
\text { that pass } \\
\text { through } \\
0.075 \mathrm{~mm} \\
\text { with } 4.5 \% \\
\text { admixture }\end{array}$ & \\
\hline 3 & $\begin{array}{c}\text { Peat soil + } \\
5 \% \text { RHA + } \\
2 \% \text { Lime }\end{array}$ & $\begin{array}{c}\text { The peat soil } \\
\text { that pass } \\
\text { through } \\
0.075 \mathrm{~mm} \\
\text { with } 7 \% \\
\text { admixture }\end{array}$ & \\
\hline 4 & $\begin{array}{l}\text { Peat soil + } \\
7.5 \% \text { RHA } \\
+2 \% \text { Lime }\end{array}$ & $\begin{array}{c}\text { The peat soil } \\
\text { that pass } \\
\text { through } \\
0.075 \mathrm{~mm} \\
\text { with } 9.5 \% \\
\text { admixture }\end{array}$ & \\
\hline 5 & $\begin{array}{l}\text { Peat soil + } \\
10 \% \text { RHA } \\
+2 \% \text { Lime }\end{array}$ & $\begin{array}{c}\text { The peat soil } \\
\text { that pass } \\
\text { through } \\
0.075 \mathrm{~mm} \\
\text { with } 12 \% \\
\text { admixture } \\
\end{array}$ & \\
\hline 6 & Peat soil & $\begin{array}{l}\text { Undisturbed } \\
\text { soil sample }\end{array}$ & UCT \\
\hline
\end{tabular}

Proctor compaction test used to determine the optimum moisture content at which a given soil type become most dense and achieve its maximum dry density. Meanwhile, the standard compaction test based on BS 1377: Part4:1990: 3.3 is applied to determine the maximum dry density and the optimum moisture content of soil. As for the compressive strength of peat soil and sawdust admixtures, the direct shear test is performed in accordance to BS 1377-7:1990 and ASTM D 3080 - 04. Under consolidated drained conditions, Standard Test Method is used for direct shear test of soils. The test is performed by deforming a specimen at a controlled rate on or near a single shear plane. Furthermore, the test was carried out at different moisture contents, but it is usual to saturate the sample before running the test. In purpose of attaining consistent results, few tests were carried out using three or four samples of undisturbed soil. The undisturbed sample soil was used to the make the specimen for UCT. The undisturbed samples were used as references to see the effect of the admixture. Meanwhile, disturbed sample was dried in oven at $105^{\circ} \mathrm{C}$ for 24 hours. The larger size of soil was gently crushed by hand to make it as fine soil grain. The soil samples then were sieved through $0.075 \mathrm{~mm}$ sieve size. The basic characteristics of untreated soil and preparation of treated soil for the mechanical properties were used by these samples. 


\section{Result and discussion}

The series of laboratory was performed including liquid limit (LL), plastic limit (PL), compaction characteristics and unconfined compressive strength values were determined for peat soils with various portion of RHA like $2.5 \%, 5 \%, 7.5 \%, 10 \%$ and $2 \%$ of hydrated lime. Another batch of peat soil were tested at different percentage of the sawdust content of $0 \%, 2 \%, 3 \%, 4 \%$ and $5 \%$ respectively from the dry weight of the soil samples.

\subsection{Atterberg limit}

Based on the obtained soil properties, even the average organic content obtained from laboratory tests indicates high organic content which is $91.05 \%$, is within the range of published data [5-6] on peat soil found in Malaysia. Using $50 \mathrm{ml}$ pycnometer test, the average specific gravity obtained is 2.16 which the value is acceptable and within the range since some researchers prove that soils with minimum organic content normally have specific gravity value less than 2.60 and some value as lower as 2.00.As for the average percentage of liquid limit (LL) and plastic limit (PL), the results are $63.44 \%$ and $48.62 \%$ respectively and it indicates low value of plasticity index (PI) $14.82 \%$ but it revealed high moisture content of soil which is $104.75 \%$. Figure 1 shows the Atterberg limit values for the treated peat soil with sawdust mixtures.

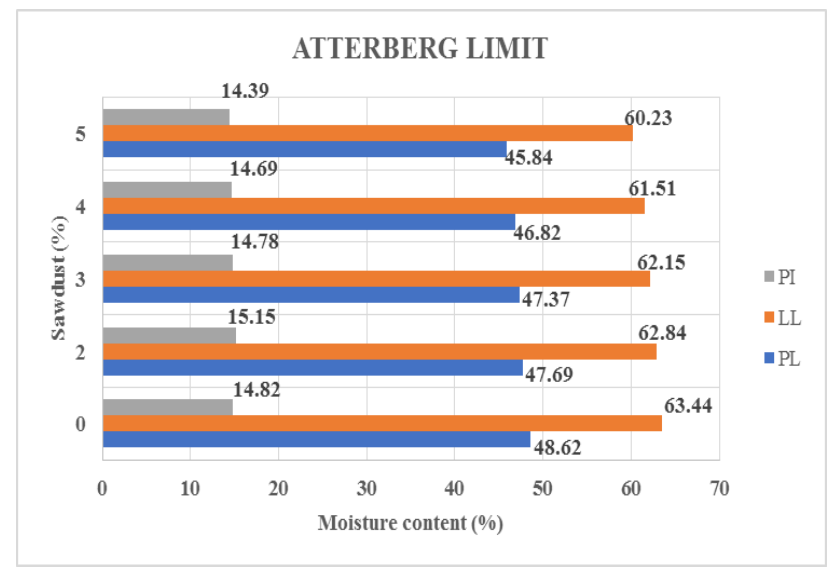

Fig. 1. Effect of peat soil and sawdust content on Atterberg limit values

Atterberg limit of treated soils was determined to In order to examine the influence of RHA contents used in treated soil, Atterberg limit test was conducted and it shown that water content drastically influences properties of finegrained soils. Depending on the moisture content, clayey and silts soils may appear in four states that are solid, semi-solid, plastic and liquid. As a hard, rigid solid in the dry state, fine grained soil becomes a crumbly (friable) semisolid when certain moisture content or shrinkage limit is reached. This soil will also begin to swell as shrinkage limit is exceeded. Increasing the water content beyond the soil's plastic limit will transform it into a plastic mass, which causes additional swelling. The soil will remain in this plastic state until its liquid limit is exceeded, which causes it to transform into a viscous liquid that flows when jarred. Figure 2 shows the Atterberg limit values for the treated soils.

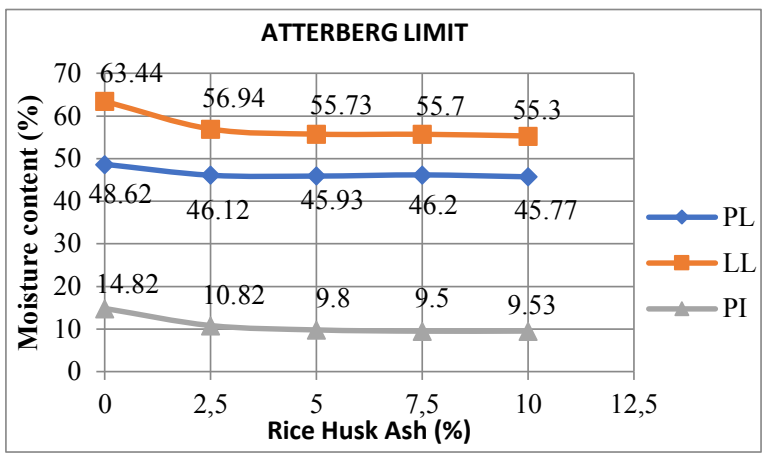

Fig. 2. Effect of Rice Husk Ash (RHA) and Hydrated Lime content on Atterberg limit values

Figure 2 shows it was clearly indicated that the values of LL and PL decreased with the increasing proportion of RHA and lime. The values of plasticity index, PI also showed a reduction trend from $14.82 \%$ to $9.5 \%$ as RHA and lime content increased up to $12 \%$. The leaning of decreasing in Atterberg limit values was apparently occurred at $4.5 \%$ of additive content from $63.44 \%$ to $55.30 \%$ for liquid limit, LL while $48.62 \%$ to $45.77 \%$ for plastic limit, PL. The drop in the values of LL and PL with increasing amounts of added additive was also reported by other researchers [7]. According to Rahman et al. (2008), it is well acknowledged that the presence of silica content and mineralogy controls the liquid and plastic limits of soil. Therefore, the reductions in liquid and plastic limits are attributed to the replacement of soil fines by the presence of additive in treated soil. As RHA and Hydrated Lime contents were increased, the ratio of soilRHA was decreased and amount of water required would be less. Beyond $4.5 \%$ of additive content, amounts of required water for both limits were slightly changed as shown by the tests. It can be generally stated that $4.5 \%$ mixture of RHA and hydrated lime is the optimum amount to reduce the plasticity of the studied soil. As comparison, the optimum content of RHA and hydrated lime added to peat soil was between 7 and 9.5\% [3]. A reduction in PI indicates an improvement to the treated soil.

\subsection{Compaction}

Compaction is an effort to increase the density of soil mass by bringing down the voids with increasing soil water content. As for the optimum water content, the density of soil is at maximum value. Subsequent amount of water added will result with reduction of soil density. Table 2 reveals the findings on how compaction is affected by sawdust contents. It is proven as the sawdust percentage increase in the mixture can extend to maximum dry unit weight with less optimum moisture content than natural soil due to absorption of moisture from the soil by sawdust. Figure 2 and Figure 3 shown the results of the compaction tests on untreated and RHA and hydrated lime treated soils. Both figures also 
indicated the comparison results of this study with others research result with a different location.

Table 2. Compaction of peat soil with different sawdust percentage

\begin{tabular}{|c|c|c|}
\hline Sample & $\begin{array}{c}\text { Optimum } \\
\text { Moisture } \\
\text { Content } \\
\mathbf{( \% )}\end{array}$ & $\begin{array}{c}\text { Maximum } \\
\text { Dry Density } \\
\text { (g/cm3) }\end{array}$ \\
\hline $\begin{array}{c}\text { Raw soil (0\% } \\
\text { sawdust) }\end{array}$ & 21.047 & 1.386 \\
\hline 2\% sawdust & 18.525 & 1.348 \\
\hline 3\% sawdust & 21.515 & 1.291 \\
\hline 4\% sawdust & 22.196 & 1.274 \\
\hline 5\% Sawdust & 20.217 & 1.226 \\
\hline
\end{tabular}

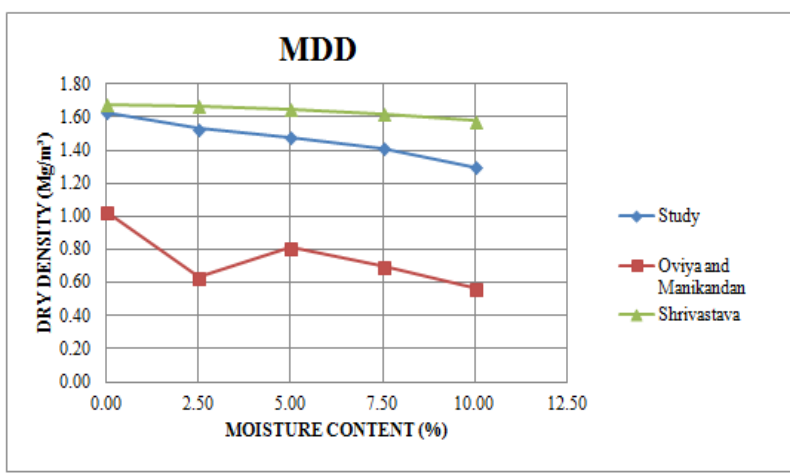

Fig. 3. Maximum dry density comparison between study and previous research



Fig. 4. Optimum moisture comparison between study and previous research

According to the result obtained, the optimum moisture content, $w_{\text {opt }}$ and maximum dry density, $\rho_{d} \max$ show declining values as the percentage of sawdust increases. The peat soil has higher dry density which is $1.386 \mathrm{~g} / \mathrm{cm}^{3}$ and $21.047 \%$ of optimum moisture content. Among the percentage of sawdust, soil sample with the addition of $4 \%$ sawdust indicates the highest moisture content of 22.196 and $1.274 \mathrm{~g} / \mathrm{cm}^{3}$ dry density For the result of the compaction tests on untreated and RHA and hydrated lime treated soils, the maximum dry density, $\rho_{d} \max$ and optimum moisture content, $w_{\text {opt }}$ of untreated soil $(0 \%)$ were $1.63 \mathrm{Mg} / \mathrm{m}^{3}$ and $13 \%$, respectively. As the added RHA contents were increased, the value of $\rho_{d} \max$ decreased from $1.63 \mathrm{Mg} / \mathrm{m}^{3}$ to $1.30 \mathrm{Mg} / \mathrm{m}^{3}$ at $10 \%$ of RHA content. It is clearly illustrated in Figure 2 that the compaction curves of RHA treated soils shifted downward to the right side of the plot. The addition of RHA into soil has caused the reduction in maximum dry density, $\rho_{d \max }$ of the treated soil is subjected to the low specific gravity of RHA $\left(\mathrm{G}_{\mathrm{s}}=2.08\right)$ [7]. RHA grains substituted the soil particles that are denser $\left(\mathrm{G}_{\mathrm{s}}=2.16\right)$ resulted in overall decrease in dry density of the treated soil. In respect to the increase in $w_{\text {opt }}$ with increasing RHA contents attributed to the coating of soil by RHA which result in formation of large particles with larger voids. It proved the findings that the surface area of soil with RHA mixture was greater caused by the decreasing of silt and clay fractions. Hence, more water will absorb by RHA to achieve maximum density. Similar behaviour of compaction characteristic was also reported by other previous studies. In a nutshell, more water will be required to compact soil with RHA mixture and the achieved maximum density will be lower than that of untreated soil due to the nature of RHA low $\mathrm{G}_{\mathrm{s}}$ value.

\subsection{Shear strength}

The shear strength parameter obtained from the direct shear test of stabilized soil samples is increased with the increasing sawdust content of $0 \%, 2 \%, 3 \%, 4 \%$ and $5 \%$ as shown in Figure 4. When the load of $50 \mathrm{kN}$ is applied, the shear strength of sawdust mixture increased from 38.1 $\mathrm{kPa}$ to $54.5 \mathrm{kPa}$. However, when the sawdust continuing been added to $5 \%$ from the dry density of soil sample the shear strength is decreased where from $54.5 \mathrm{kPa}$ to 51.8 $\mathrm{kPa}$.

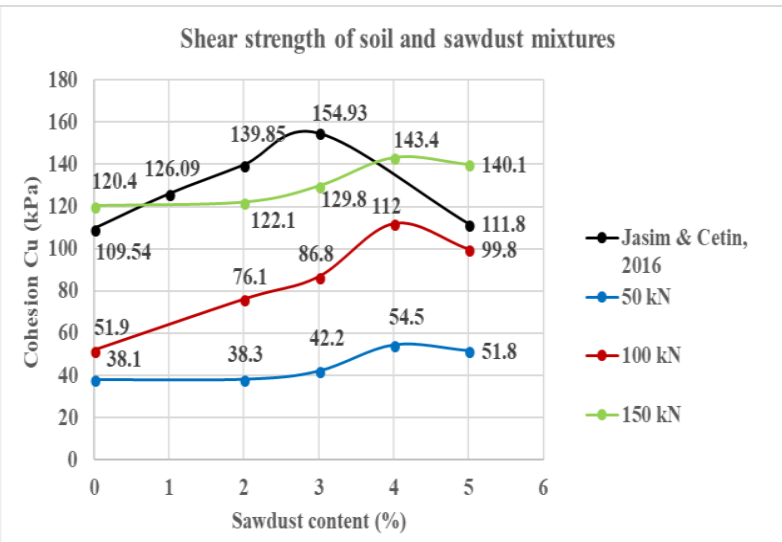

Fig. 5. The shear strength parameter obtained from direct shear test of stabilized soil with sawdust content

A comparative study has been conducted to the research by [4], the cohesion strength due to unconfined compressive test of mixture is increased by $41.437 \%$ at $3 \%$ of sawdust content and it decreasing when sawdust content reaches $5 \%$. From the curvature in the graph of Figure 4, this study profound the maximum shear strength of mixture occurs at $4 \%$ sawdust content. The experimental results are attributed to soil-sawdust 
reaction besides designate that the sawdust works as filler for the gap in the soil particles.

The most common and adaptable method of evaluating the strength of stabilized soil is Unconfined compressive strength (UCS). It is the main test recommended for the determination of the required amount of additive to be used in the stabilization of soil. Variation of UCS with the increase in RHA from $2.5 \%$ to $10 \%$ was investigated and the results are shown in Figure 5.

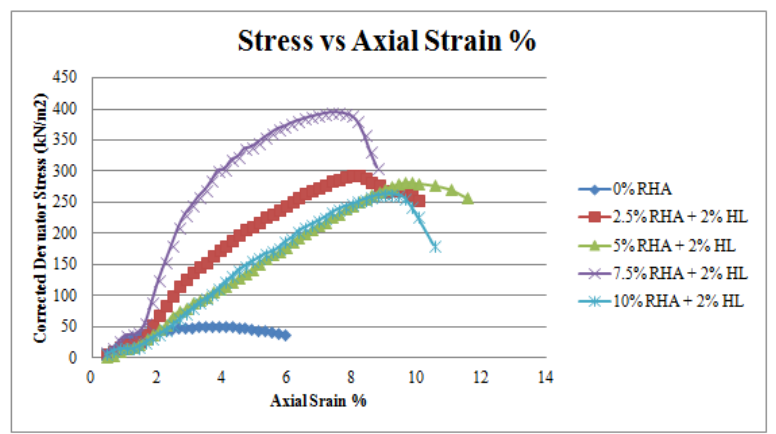

Fig. 6. Stress vs. strain curves of treated soils at different RHA content

Figure 5 shows that the UCS value for is increasing with the increase in RHA content at percentage intervals from $2.5 \%$ to $10 \%$ and the comparison with previous study respectively. The UCS value of the natural peat soil was found to be $51.8 \mathrm{kN} / \mathrm{m}^{2}$. With the addition of $2.5 \%$ of RHA, the UCS value increased to $294.3 \mathrm{kN} / \mathrm{m}^{2}$. On Further addition of 5\% of RHA to the soil, the UCS value was decreased to $282.4 \mathrm{kN} / \mathrm{m}^{2}$. After that, the UCS value increases with addition of RHA content in the soil. The value then was decreased at $10 \%$ of RHA. This is because due to clay content reduction in soil. This results in reduction of cohesive force in the soil sample. The graph also shown the optimum RHA in this study is $7.5 \%$. In addition, initially RHA with high silica content forms the cementations compound giving the good cohesion. When the RHA content increases in the soil, it slows down the pozzolanic reaction by occupying the void spaces in the soil and reducing the bond between soil and RHA mixtures. On excess addition of RHA, the reaction between the $\mathrm{CaOH}$ in the soil and rice husk ash becomes slow which results in weak bonding between soil-RHA mixtures. Addition of lime is added at a constant rate of $2 \%$ to improve the strength of soil and RHA admixture. On reaction of lime with silica, it produced cementations material and binds together with the soil. But, according to [3], the addition of lime more than $2 \%$ with RHA is not beneficial in strength.

\section{Conclusion}

In this experimental study, the effect of sawdust content and RHA on geotechnical properties of the soil are investigated and analyzed. Overall, it can be deduced that the findings are promising and improving results are profound in stabilizing the soil with sawdust and Rice Husk Ash in both economic and strength capacity. This will not only solve the waste disposal problem but also enhance the strength characteristics of soil significantly. From the results obtained, the following conclusion can be made:

1. The optimum result for physical properties of the sawdust and peat soil using different mixtures are determined which is soil sample with $4 \%$ of sawdust content, resulted 2.05 of specific gravity, $46.82 \%$ of plastic limit, $61.51 \%$ of liquid limit and $14.69 \%$ of plasticity index. The liquid limit and plastic limit of the soil is decreasing with the percentage increase of RHA due to the presence of silica content and mineralogy that controls the liquid and plastic limits of soil. Thus, the replacement of soil fines by the presence of additive in treated soil is related with the reductions in liquid and plastic limits

2. Soil sample with addition of $4 \%$ sawdust indicates the highest moisture content and dry density of 22.196 and $1.274 \mathrm{~g} / \mathrm{cm} 3$ respectively. It shown that increasing in sawdust percentage in the mixture can extend to maximum dry unit weight with less optimum moisture content than natural soil since sawdust itself absorb the moisture from the soil. In addition, the maximum dry density (MDD) of the soil decreases with the addition of RHA due to lower specific gravity of RHA. The optimum moisture content (OMC) of the soil increases on stabilizing with RHA because of pozzolanic reaction between $\mathrm{CaOH}$ of the soil and RHA.

3. Soil with addition of $4 \%$ sawdust content provides the optimum shear strength is pointed out the highest cohesion and angle of shearing resistance; $14.4 \mathrm{kPa}$ and $41.637^{\circ}$ with highest shear strength of $143.4 \mathrm{kPa}, 112 \mathrm{kPa}$ and $54.5 \mathrm{kPa}$ for $50 \mathrm{kN}, 100 \mathrm{kN}$ and $150 \mathrm{kN}$ of loading in the direct shear test. The UCS value gets increased to high limit at an optimum value of $7.5 \%$ of RHA content and $2 \%$ of lime. It is also being concluded that for the improvement in strength using stabilization in practical purposes, these optimum value percentage values of RHA and lime can be recommended for construction. But addition of lime and RHA beyond this limit to the soil is not beneficial and workable.

Sincere gratitude offer to the previous honours students and technician in the soil mechanics laboratory for their help in undertaking the experimental work. The author also wishes to extend appreciation to Faculty of Civil Engineering, Universiti Teknologi MARA to provide required funding support and facilities for this research. 


\section{References}

1. Hashim, R., Islam, S., \& Lumpur, K., Engineering Properties of Peat Soils in Peninsular, Malaysia. Journal of Applied Sciences (2008)

2. Shafie, S. M., Paddy residue based power generation in Malaysia: Environmental assessment using LCA approach. ARPN Journal of Engineering and Applied Sciences, 10, 6643-6648 (2015)

3. Oviya R. \& Manikandan R., An Experimental Investigation On Stabilizing The Soil Using Rice Husk Ash With Lime As Admixture. 3, 3511-3519 (2016)

4. Jasim, O. H., \& Cetin, D., Effect of Sawdust Usage on The Shear Strength Behavior of Clayey Silt Soil. Sigma Journal Engineering and Natural Sciences, 31$41(2016)$

5. Huat, B. B. K., Maail, S., \& Mohamed, T. A. Effect of Chemical Admixtures on the Engineering Properties of Tropical Peat Soils. American Journal of Applied Sciences (2005)

6. Zainorabidin, A., \& Wijeyesekera, D. C., Geotechnical Challenges with Malaysian Peat. Advances in Computing and Technology, The School of Computing and Technology $2^{\text {nd }}$ Annual Conference. Proceeding of the AC \& T, London (252-261) (2007)

7. Rahman, Z. A., Ashari, H. H., Sahibin, A. R., Tukimat, L., \& Razi, I. W. M., Effect of Rice Husk Ash Addition on Geotechnical Characteristics of Treated Residual Soil, 14, 1368-1377 (2014) 